\title{
CẢM NHÂ̂N CỦA KHÁCH HÀNG VỀ CHẤT LƯợNG DỊCH VỤ TIÊM NộI NHÃN ĐIỀU TRI MộT SỐ BỆNH MACH MÁU VÕNG MẠC TẠI BÊ̂NH VIỆN MẮT TRUNG ƯƠNG NĂM 2020
}

\section{TÓM TĂT}

Mục tiêu: Chất lượng dịch vụ có vai trò quan trọng, là một trong những nhân tố quyết định sự tồn tại, thành công cũng như góp phân xây dựng uy tín, hình ảnh thương hiệu của tổ chức. nghiên cứu của chúng tôi được thực hiên nhằm mục tiêu mô tả cảm nhận của khách hàng về chất lượng dịch vụ tiêm nội nhã̃n điều trị một số bênh mạch máu võng mạc và phân tích một sổ yếu tổ ảnh hưởng tại BV Mắt Trung ương năm 2020. Phương pháp: Nghiên cứu mô tả cắt ngang, kết hợp nghiên cứu định lượng và nghiên cứu đinh tính. Nighiên cứu được thực hiện tại Bệnh viện Mắt Trưng ương từ tháng 10/2019 đến đến tháng 02/2020. Mấu nghiên cứu gồm 88 khách hàng đã sứ dụng dịch vụ tiêm nội nhãn. Chất lượng dịch vụ được đánh giá bắng thang đo SERVPERF. Kết quả: Điếm đánh giá trung bình đạt $4.24 \pm 0.041$ trên trên thang đo Likert có giá trị tối đa 5 điểm. Khía cạnh sự đảm bảo đạt điểm cao nhất trong các cấu phần (điểm trung bình 4.45), điểm trung bình các khía canh tin cậy, hữu hình, đáp ứng, cảm thông lần lượt là 4.36; $4.16 ; 4.12$ và 4.10 điểm. Kết luận: Kết quả nghiên cứu cho thấy người bệnh đánh giá tốt chất lượng dịch vụ tiêm nội nhãn do Bệnh viện Mắt Trung Ương cung cấp. Bệnh viên cần tiếp tục duy trì các biện pháp tăng cường chất lượng dich vụ nhãn

Từ khóa: Chất lượng dịch vụ, SERVPERF, tiêm nội

\section{SUMMARY}

ASSESSMENT OF CLIENTS PERCEPTION ON QUALITY OF SERVICES FOR INTRAVITREAL INJECTION AT VIETNAM NATIONAL INSTITUTE OF OPHTHALMOLOGY IN 2019

Objective: Service quality is one of the determining factors in the success of any hospital, enhancing not only the reputation and brand image but also the competitiveness of the hospital, all of which contributes largely to attracting and retaining customers, as well as improving satisfaction. This study aims to assess the perception of clients who use the intravitreal injection and analyze several factors influencing the quality of this service at Vietnam National Institute of Ophthalmology in 2019. Methods: Descriptive cross-sectional study combined with qualitative research. Sample included 88 clients used

${ }^{1}$ Trường Đại họ Y tế công cộng

²Bênh viện Mắt Trung Ương

Chịu trách nhiệm chính: Vũ Thị Hoàng Lan

Email: Vhl@huph.edu.vn

Ngày nhận bài: 5.3.2021

Ngày phản biện khoa học: 26.4.2021

Ngày duyệt bài: 7.5.2021

\section{Vũ Thị Hoàng Lan ${ }^{1}$, Đặng Trần Đạt ${ }^{2}$}

intravitreal injection services at VNIO during 10/2019 to 2/2020. Quality of services were assessed using SERVPERF model with 5 components of service quality. Results: The result for customer perception on the quality of intravitreal injection service in VNIO on SERVPERF scale reached $4.24 \pm 0.041$ points. Customer perception is highest in terms of Assurance with 4.45 points while aspects of Reliability, Tangible, Response, Empathy gain an average score of 4.36; $4.16 ; 4.12 ; 4.10$ points respectively. Conclusions: Overall, client's perception of quality of intravitreal injection services in VNIO was good. VNIO need to continue maintain and improve this service quality.

Keywords: quality services, SERVPERF, intravitreal injection

\section{I. ĐẶT VẤN ĐỀ}

Chất lượng dịch vụ có vai trò quan trọng, là một trong những nhân tố quyết định sự tồn tại, thành công cũng như góp phân xây dựng uy tín, hình ảnh thương hiệu của tổ chức. Trong nghiên cứu của Cronnin và Taylor được tiến hành vào năm 1992 đã đề xuất mô hình SERVPERF đo lường chất lượng cung cấp dịch vụ. Chất lượng dịch vụ được cảm nhận bởi khách hàng là một kiểu thái độ, một sự đánh giá mang tính lâu dài của khách hàng về chất lượng dịch vụ; trong khi đó sự hài lòng khách hàng về chất lượng dịch vụ là khái niệm liên quan đến việc đo lường một sự chuyển giao dịch vụ cụ thể[1,2].

Các bệnh lý mạch máu võng mạc như thoái hóa hoàng điểm tuổi già, bệnh võng mạc do đái tháo đường, tắc tĩnh mạch võng mạc là một trong các nguyên nhân hàng đâu đe dọa mất thị lực trên thế giới. Các bệnh lý này khá phổ biến ở các nước phát triển cũng như ngày càng gia tăng ở các nước đang phát triển và trước đây việc điều trị gặp nhiều khó khăn[3-5]. Gân đây với việc điều trị đích bằng cách tiêm nội nhãn các thuốc ức chế tăng sinh nội mạc mạch (VEGF) trong đó có thuốc bevacizumab đã tạo ra cuộc cách mạng trong điều trị các bệnh lý nặng này. Lân đâu tiên các bệnh nhân mắc các bệnh lý này có thể cải thiện và phục hồi được thị lực, tránh nguy cơ mù lò̀a nâng cao chất lượng cuộc sống cho bệnh nhân. Bệnh viện Mắt Trung ương đã thực hiện thủ thuật tiêm nội nhãn cho rất nhiêu bệnh nhân trong thời gian qua, tuy nhiên hiện chưa có nghiên cứu đánh giá cảm nhận của khách hàng về chất lượng của loại dịch vụ này, 
về những kỳ vọng của họ và các giá trị đích thực mà bệnh viện đã mang đến cho họ. Chính vì lý do trển, nghiên cứu của chúng tôi được thực hiện nhằm mục tiêu mô tả cảm nhận của khách hàng về chất lượng dịch vụ tiêm nội nhãn điều trị một số bệnh mạch máu võng mạc và phân tích một số yếu tố ảnh hưởng tại BV Mắt Trung ương năm 2020.

\section{II. ĐỐI TƯợNG VÀ PHƯƠNG PHÁP NGHIÊN CỨU}

Thiết kế nghiên cứu. Nghiên cứu mô tả cắt ngang, kết hợp nghiên cứu định lượng và nghiên cứu định tính. Nghiên cứu được thực hiện tại Bênh viên Mắt Trung ương từ tháng 10/2019 đến đến tháng 02/2020. Mẫu nghiên cứu gồm 88 khách hàng đã sử dụng dịch vụ tiêm nội nhãn. Đồng thời, một số nhân viên y tế cũng được chọn vào nghiển cứu để tìm hiểu các yếu tố ảnh hưởng đến từ góc nhìn của nhà cung cấp dịch vụ.

Biến số/chỉ số/ nội dung/chủ đề nghiên cứu. Các biến số chính để đo lường cảm nhận của khách hàng gồm 05 khía canh với 22 biến theo thang đo SERVPERF đã được chuẩn hoá: 1 ) Khía cạnh phương tiện hữu hình với 04 tiểu mục, thể hiện qua trực quan về cơ sở vật chất, trang thiết bị, trang phục của nhân viên; 2) Khía cạnh sự tin cậy gồm 05 tiểu mục thể hiện qua khả nắng thực hiện dịch vụ đã hứa hẹn một cách đáng tin cậy và chính xác; 3) Khía cạnh sự đáp ứng với 04 tiểu mục thể hiện qua sự mong muốn, sẵn sàng của nhân viên cung cấp dịch vụ kịp thời cho khách hàng; 4) Khía cạnh sự đảm bảo với 04 tiểu mục thể hiên qua trình đô chuyên môn và thái độ phục vụ lịch sự, niềm nở của nhân viên làm cho khách hàng tin tưởng; 5) Khía cạnh sự cảm thông với 05 tiểu mục thể hiện qua sự quan tâm, ân cần, chăm sóc đến từng khách hàng. Chủ đề nghiên cứu định tính bao gồm các yếu tố về nhân sự, chính sách và trang thiết bị, cơ sở vật chất có ảnh hưởng đến cảm nhận về chất lượng dịch vụ từ góc nhìn của nhà cung cấp dịch vụ.

Xử lý và phân tích số liệu. Số liệu nghiên cứu sau khi thu thập được tiển hành làm sạch, mã hoá, nhập liệu vào phần mềm Epidata 3.1 và phân tích bằng phần mềm SPSS 20.0. Kỹ thuật thống kê mô tả được sử dụng để tính các giá trị tần số, tần suất, trung bình, độ lệch chuẩn.

\section{KẾT QUẢ NGHIÊN CứU}

Đặc điểm chung của các đối tượng nghiển cứu. Bảng 1 cho thấy nghiên cứu thực hiện khảo sát trên 88 ĐTNC đã sử dụng thủ thuật tiêm nội nhãn bằng các thuốc ứng chế tăng sinh nội mạc mạch, nhóm tuổi có tỷ lệ cao nhất là nhóm $>60$ tuổi (chiếm $50 \%$ ) và thấp nhất là nhóm < 30 tuổi (chiếm 3,2\%), nhóm tuổi từ 30 - 60 tuổi chiếm 46,6\%. Về giới tính, có 63 khách hàng là nam giới trong nghiên cứu này (chiếm tỷ lệ $73,9 \%$ ) và 23 khách hàng là nữ giới (chiếm 26,1\%). Riêng câu hỏi với nhiều sự lựa chọn về kênh thông tin khách hàng biết đên dịch vụ thủ thuật tiêm nội nhãn bằng các thuốc ứng chế tăng sinh nội mạc mạch của bệnh viện thì có đến 77 câu trả lời cho biết là được nhân viên của bệnh viện tư vấn (chiếm tỷ lệ 57,9\%), 34 câu trả lời biết đến thông tin này qua người quen giới thiệu $(25,6 \%)$ và 22 câu trả lời (tỷ lệ 16,5\%) tìm hiểu thông tin trên các phương tiện thông tin đại chúng như báo, internet..

Bảng 1. Một số đặc điểm nhân khẩu học của đôí tượng nghiển cứu

\begin{tabular}{|c|c|c|c|}
\hline \multicolumn{2}{|r|}{ Đặc điểm } & \multirow{2}{*}{$\begin{array}{c}\mathbf{N} \\
3\end{array}$} & \multirow{2}{*}{$\begin{array}{c}\text { Tỷ lệ (\%) } \\
3,4\end{array}$} \\
\hline \multirow{3}{*}{$\begin{array}{c}\text { Nhóm } \\
\text { tuổi }\end{array}$} & $<30$ & & \\
\hline & $30-60$ & 41 & 46,6 \\
\hline & $>60$ & 44 & 50,0 \\
\hline \multirow{2}{*}{$\begin{array}{l}\text { Giới } \\
\text { tính }\end{array}$} & Nam & 65 & 73,9 \\
\hline & Nũ̃ & 23 & 26,1 \\
\hline \multirow{5}{*}{$\begin{array}{l}\text { Trình } \\
\text { độ học } \\
\text { vân }\end{array}$} & Tiếu học & 31 & 35,2 \\
\hline & THCS & 15 & 17,0 \\
\hline & THPT & 9 & 10,2 \\
\hline & Trung cấp, cao đằng & 19 & 21,6 \\
\hline & Đại học, Sau Đại học & 14 & 15,9 \\
\hline \multirow{4}{*}{$\begin{array}{l}\text { Nghề } \\
\text { nghiệp }\end{array}$} & Nồng dấn, công nhần & 20 & 22,7 \\
\hline & Công chức, viên chức & 21 & 23,9 \\
\hline & Nghề tự do & 20 & 22,7 \\
\hline & Hưu trí & 27 & 30,7 \\
\hline \multirow{4}{*}{$\begin{array}{c}\text { Kênh } \\
\text { tiếp } \\
\text { nhận } \\
\text { thông } \\
\text { tin }\end{array}$} & $\begin{array}{l}\text { Thông tin trên báo, đài, } \\
\text { internet... }\end{array}$ & 22 & $16,5 \%$ \\
\hline & Người quen giới thiệu & 34 & $25,6 \%$ \\
\hline & Nhân viền của BV tư vấn & 77 & $57,9 \%$ \\
\hline & Nguồn khác & 0 & 0,0 \\
\hline
\end{tabular}

Cảm nhận của khách hàng về từng khía cạnh chất lượng cung cấp dịch vụ thủ thuật tiêm nội nhãn bằng các thuốc ứng chế tăng sinh nội mạc mạch tại Bệnh viện Mắt Trung Ương

Kết quả đánh giá cảm nhận của khách hàng về chất lượng cung cấp dịch vụ thủ thuật tiêm nội nhãn bằng các thuốc ứng chế tăng sinh nội mạc mạch tại Bệnh viện Mắt Trung Ương theo thang đo SERVPERF đạt 4,24 $\pm 0,041$ điểm. Các khía cạnh có số điểm trung bình từ cao đến thấp lân lượt là: sự đảm bảo với mức điểm trung bình 4,45 $\pm 0,043$ điểm, sự tin cậy đạt 4,36 $\pm 0,041$ điểm, phương tiện hữu hình đạt $4,16 \pm 0,047$ điểm, sự đáp ứng đạt $4,12 \pm 0,054$ điểm và sự cảm thông đạt 4,10 $\pm 0,049$ điểm. 
Bảng 2: Đánh giá chất lượng về khía cạnh phương tiện hữu hình

\begin{tabular}{|c|c|c|c|c|c|c|}
\hline Nội dung & $\begin{array}{c}\text { Rất kém } \\
\mathbf{n}(\%)\end{array}$ & $\begin{array}{c}\text { Kém } \\
\mathbf{n}(\%)\end{array}$ & $\begin{array}{c}\text { Trung bình } \\
\mathbf{n}(\%)\end{array}$ & $\begin{array}{c}\text { Tốt } \\
\mathbf{n}(\%)\end{array}$ & $\begin{array}{c}\text { Rất tốt } \\
\mathbf{n}(\%)\end{array}$ & $\begin{array}{c}\text { Điếm trung } \\
\text { bình } \pm \text { SD }\end{array}$ \\
\hline $\begin{array}{c}\text { Cơ sở vật chất } \\
\text { sạch, đẹp }\end{array}$ & 0 & 0 & $17(17 \%)$ & $58(65,9 \%)$ & $17(17 \%)$ & $4,00 \pm 0,587$ \\
\hline $\begin{array}{c}\text { Trang thiết bị } \\
\text { hiện đại }\end{array}$ & 0 & 0 & $6(6,8 \%)$ & $58(65,9 \%)$ & $24(27,3 \%)$ & $4,20 \pm 0,550$ \\
\hline $\begin{array}{c}\text { Tài liệu truyền } \\
\text { thông đây đủ }\end{array}$ & 0 & 0 & $16(18,2 \%)$ & $56(63,6 \%)$ & $16(18,2 \%)$ & $4,00 \pm 0,606$ \\
\hline $\begin{array}{c}\text { Trang phục } \\
\text { NVYT gọn gàng }\end{array}$ & 0 & 0 & $\begin{array}{c}2 \\
(2,3 \%)\end{array}$ & $47(53,4 \%)$ & $39(44,3 \%)$ & $4,42 \pm 0,541$ \\
\hline
\end{tabular}

Qua kết quả tại bảng 2, ĐTB cảm nhận của KH ở khía cạnh phương tiện hữu hình đạt 4,16 \pm 0,047 điểm. Tiểu mục TAN4 "Trang phục NVYT gọn gàng, sạch sẽ" có ĐTB cao nhất là 4,42 $\pm 0,541$, TAN1 "Cơ sở vật chất sach, đẹp" và TAN3 "Tài liêuu truyên thông đầy đủ" có số ĐTB bằng nhau là 4,00 điểm. Tiểu mục TAN2 "Trang thiết bị hiện đại" đạt 4,20 $\pm 0,550$ điểm.

Bảng 3: Đánh giá chât lượng về khía cạnh phương tiện hữu hình

\begin{tabular}{|c|c|c|c|c|c|c|}
\hline Nội dung & $\begin{array}{c}\text { Rất kém } \\
\mathbf{n}(\%)\end{array}$ & $\begin{array}{c}\text { Kém } \\
\mathbf{n}(\%)\end{array}$ & $\begin{array}{c}\text { Trung bình } \\
\mathbf{n}(\%)\end{array}$ & $\begin{array}{c}\text { Tốt } \\
\mathbf{n}(\%)\end{array}$ & $\begin{array}{c}\text { Rất tốt } \\
\mathbf{n}(\%)\end{array}$ & $\begin{array}{c}\text { Điểm trung } \\
\text { bình } \pm \text { SD }\end{array}$ \\
\hline $\begin{array}{c}\text { Thực hiện dịch } \\
\text { vụ đúng cam kết }\end{array}$ & 0 & 0 & $\begin{array}{c}2 \\
(2,3 \%)\end{array}$ & $59(67 \%)$ & $27(30,7 \%)$ & $4,28 \pm 0,053$ \\
\hline $\begin{array}{c}\text { Kết quả đúng } \\
\text { hẹn, chính xác }\end{array}$ & 0 & 0 & $\begin{array}{c}2 \\
(2,3 \%)\end{array}$ & $59(67 \%)$ & $27(30,7 \%)$ & $4,28 \pm 0,053$ \\
\hline $\begin{array}{c}\text { Thực hiến công } \\
\text { việc đúng hẹn, } \\
\text { đúng giờ }\end{array}$ & 0 & 0 & $\begin{array}{c}7 \\
(8 \%)\end{array}$ & $60(68,2 \%)$ & $21(23,9 \%)$ & $4,16 \pm 0,058$ \\
\hline $\begin{array}{c}\text { NV tư vấn tận } \\
\text { tình, rõ ràng }\end{array}$ & 0 & 0 & $\begin{array}{c}2 \\
(2,3 \%)\end{array}$ & $36(40,9 \%)$ & $50(56,8 \%)$ & $4,55 \pm 0,058$ \\
\hline Dịch vụ an toàn & 0 & 0 & $1(1,1 \%)$ & $39(44,3 \%)$ & $48(54,5 \%)$ & $4,53 \pm 0,056$ \\
\hline
\end{tabular}

Kết quả tại bảng 3 cho thấy, tiếu mục REL4 "NVYT tư vấn tận tình, rõ ràng" đạt ĐTB cao nhất là 4,55 $\pm 0,058$ điểm cho thấy khách hàng cảm nhận rất tốt nội dung này. Mục REL5 "Dịch vụ an toàn" cũng nhận được sự tin tưởng và đánh giá cao với số điểm trung bình 4,53 $\pm 0,056$. Bên cannh đó, tiểu mục KH có đánh giá thấp nhất ở khía cạnh này là REL3 "Thực hiên công việc đúng hẹn, đúng giờ" đạt $4,16 \pm 0,058$ điểm. Hai tiểu mục đánh giá về "Thực hiện dịch vụ đúng cam kết" và "Kết quả đủng hẹn, chính xác" có kết quả bằng nhau là 4,28 điểm.

\section{Bảng 4: ĐTB chất lượng về khía cạnh sự đáp ứng}

\begin{tabular}{|c|c|c|c|c|c|c|}
\hline Nội dung & $\begin{array}{c}\text { Rất kém } \\
\mathbf{n}(\%)\end{array}$ & $\begin{array}{c}\text { Kém } \\
\mathbf{n}(\%)\end{array}$ & $\begin{array}{c}\text { Trung bình } \\
\mathbf{n}(\%)\end{array}$ & $\begin{array}{c}\text { Tốt } \\
\mathbf{n}(\%)\end{array}$ & $\begin{array}{c}\text { Rất tốt } \\
\mathbf{n}(\%)\end{array}$ & $\begin{array}{c}\text { Điếm trung bình } \\
\pm \text { SD }\end{array}$ \\
\hline $\begin{array}{c}\text { Thông tin khách } \\
\text { hàng cần luôn } \\
\text { được giải quyết }\end{array}$ & 0 & 0 & $\begin{array}{c}8 \\
(9,1 \%)\end{array}$ & $\begin{array}{c}57 \\
(64,8 \%)\end{array}$ & $\begin{array}{c}23 \\
(26,1 \%)\end{array}$ & $4,17 \pm 0,061$ \\
\hline $\begin{array}{c}\text { Giải quyết nhanh } \\
\text { chóng }\end{array}$ & 0 & 0 & $\begin{array}{c}14 \\
(15,9 \%)\end{array}$ & $\begin{array}{c}56 \\
(63,6 \%)\end{array}$ & $\begin{array}{c}18 \\
(20,5 \%)\end{array}$ & $4,05 \pm 0,064$ \\
\hline $\begin{array}{c}\text { Liên lạc, trao đối } \\
\text { dễ dàng với } \\
\text { NVYT }\end{array}$ & 0 & 0 & $\begin{array}{c}9 \\
(10,2 \%)\end{array}$ & $\begin{array}{c}55 \\
(62,5 \%)\end{array}$ & $\begin{array}{c}24 \\
(27,3 \%)\end{array}$ & $4,17 \pm 0,063$ \\
\hline $\begin{array}{c}\text { Kết quả điêu trị } \\
\text { cập nhật thương } \\
\text { xuyên }\end{array}$ & 0 & 0 & $\begin{array}{c}11 \\
(12,5 \%)\end{array}$ & $\begin{array}{c}56 \\
(63,6 \%)\end{array}$ & $\begin{array}{c}21 \\
(23,9 \%)\end{array}$ & $4,11 \pm 0,063$ \\
\hline
\end{tabular}

Ơ bảng 4, ĐTB khía cạnh sự đáp ứng đạt 4,12 $\pm 0,054$ điếm. Có hai tiếu mục được đánh giá cao nhất ở khía cạnh này, đạt kết quả 4,17 điểm là RES1 "Thông tin khách hàng cần luôn được giải quyết" và "Liên lạc, trao đổi dễ dàng với NVYT".

\section{Bảng 5: ĐTB chất lượng về khía cạnh sự đảm bảo}

\begin{tabular}{|c|c|c|c|c|c|c|}
\hline Nội dung & $\begin{array}{c}\text { Rất kém } \\
\mathbf{n}(\%)\end{array}$ & $\begin{array}{c}\text { Kém } \\
\mathbf{n}(\%)\end{array}$ & $\begin{array}{c}\text { Trung bình } \\
\mathbf{n}(\%)\end{array}$ & $\begin{array}{c}\text { Tốt } \\
\mathbf{n}(\%)\end{array}$ & $\begin{array}{c}\text { Rất tốt } \\
\mathbf{n}(\%)\end{array}$ & $\begin{array}{c}\text { Điếm trung bình } \\
\pm \text { SD }\end{array}$ \\
\hline NVYT có trình & 0 & 0 & 0 & $31(35,2 \%)$ & $57(64,8 \%)$ & $4,65 \pm 0,051$ \\
\hline
\end{tabular}


TẠP CHÍ Y HỌC VIỆT NAM TẬP 502 - THÁNG 5 - SỐ 1 - 2021

\begin{tabular}{|c|c|c|c|c|c|c|}
\hline độ, kinh nghiệm & & & & & \\
\hline $\begin{array}{c}\text { NVYT thân thiện, } \\
\text { cởi mở }\end{array}$ & 0 & 0 & $\begin{array}{c}3 \\
(3,4 \%)\end{array}$ & $51(58 \%)$ & $34(38,6 \%)$ & $4,35 \pm 0,058$ \\
\hline $\begin{array}{c}\text { NVYT trả lời } \\
\text { được và rõ ràng } \\
\text { những thắc mắc }\end{array}$ & 0 & 0 & $\begin{array}{c}2 \\
(2,3 \%)\end{array}$ & $60(68,2 \%)$ & $26(29,5 \%)$ & $4,27 \pm 0,053$ \\
\hline Cảm thấy an tâm & 0 & 0 & $1(1,1 \%)$ & $39(44,3 \%)$ & $48(54,5 \%)$ & $4,53 \pm 0,056$ \\
\hline
\end{tabular}

Nhìn vào bảng 5 , ĐTB đánh giá ở khía cạnh sự đảm bảo đạt 4,45 $\pm 0,043$ điểm, kết quả cho thấy khách hàng cảm nhận rất tốt ở khía cạnh này khi ĐTB đạt kết quả khá cao theo thang Likert tối đa 5 điểm.

Bảng 6: ĐTB chất lượng về khía cạnh sự cảm thông

\begin{tabular}{|c|c|c|c|c|c|c|}
\hline Nội dung & $\begin{array}{c}\text { Rất kém } \\
\mathbf{n}(\%)\end{array}$ & $\begin{array}{c}\text { Kém } \\
\mathbf{n}(\%)\end{array}$ & $\begin{array}{c}\text { Trung bình } \\
\mathbf{n}(\%)\end{array}$ & $\begin{array}{c}\text { Tốt } \\
\mathbf{n}(\%)\end{array}$ & $\begin{array}{c}\text { Rất tốt } \\
\mathbf{n}(\%)\end{array}$ & $\begin{array}{c}\text { Điếm trung } \\
\text { bình } \pm \text { SD }\end{array}$ \\
\hline $\begin{array}{c}\text { NVYT luôn thế hiện sự } \\
\text { quan tâm }\end{array}$ & 0 & 0 & $\begin{array}{c}3 \\
(3,4 \%)\end{array}$ & $\begin{array}{c}66 \\
(75,0 \%)\end{array}$ & $\begin{array}{c}19 \\
(21,6 \%)\end{array}$ & $4,18 \pm 0,050$ \\
\hline $\begin{array}{c}\text { Khách hàng luôn nhận } \\
\text { được sự tôn trọng }\end{array}$ & 0 & 0 & $\begin{array}{c}2 \\
2\end{array}$ & $\begin{array}{c}57 \\
(2,3 \%)\end{array}$ & $\begin{array}{c}29 \\
(64,8 \%)\end{array}$ & $4,31 \pm 0,054$ \\
\hline $\begin{array}{c}\text { Thấu hiếu, thông cảm } \\
\text { những khó khăn của } \\
\text { khách hàng }\end{array}$ & 0 & 0 & $\begin{array}{c}11 \\
(12,5 \%)\end{array}$ & $\begin{array}{c}54 \\
(61,4 \%)\end{array}$ & $\begin{array}{c}23 \\
(26,1 \%)\end{array}$ & $4,14 \pm 0,065$ \\
\hline $\begin{array}{c}\text { BV có những dịch vụ } \\
\text { hốn trợ }\end{array}$ & 0 & $\begin{array}{c}3 \\
(3,4 \%)\end{array}$ & $\begin{array}{c}25 \\
(28,4 \%)\end{array}$ & $\begin{array}{c}49 \\
(55,7 \%)\end{array}$ & $\begin{array}{c}11 \\
(12,5 \%)\end{array}$ & $3,77 \pm 0,075$ \\
\hline $\begin{array}{c}\text { Thời gian thuận tiện, } \\
\text { phù hợp }\end{array}$ & 0 & 0 & $10(11,4 \%)$ & $\begin{array}{c}58 \\
(65,9 \%)\end{array}$ & $\begin{array}{c}20 \\
(22,7 \%)\end{array}$ & $4,11 \pm 0,061$ \\
\hline
\end{tabular}

Điểm cảm nhân ở khía canh sư cảm thông có ĐTB đạt 4,10 $\pm 0,049$ điểm. Có $4 / 5$ tiểu mục có mức ĐTB đạt từ 4,0 trở lên. Tiểu mục duy nhất có mức ĐTB $<4,0$ là EMP4 "Bệnh viện có những dich vu hỗ trơ", đat $3,77 \pm 0,075$ điểm. ĐTB cao nhất đạt 4,31 $\pm 0,054$ điểm là EMP2 "Khách hàng luôn nhận được sự tôn trọng". Các tiểu mục còn lại có điểm trung bình lần lượt từ thấp đến cao: "Thời gian thuận tiện, phù hợp" đạt 4,11 \pm 0,061 điểm; "Thấu hiểu, thông cảm những khó khăn của khách hàng" đạt 4,14 \pm 0,065 điểm; "NVYT luôn thể hiện sự quan tâm" đạt 4,18 $\pm 0,050$ điểm.

Các yếu tố ảnh hưởng đến chất lượng cung cấp dịch vụ thủ thuật tiêm nội nhãn bằng các thuốc ứng chế tăng sinh nội mạc mạch tại Bệnh viện Mắt Trung Ương

Trong kết quả phân tích định tính từ những NVYT, nghiên cứu cho thấy các yếu tố về nhân sự, chính sách và trang thiết bị, cơ sở vật chất có ảnh hưởng đến cảm nhận về chất lượng dich vụ từ góc nhìn của nhà cung cấp dịch vụ. Bệnh viện có đội ngũ nhân viên y tế đủ năng lực, trình độ, nhiêu kinh nghiệm, tư vấn tận tình và rõ ràng những thông tin cần thiết. Bệnh viện có chính sách rõ ràng góp phần định hướng mọi công tác, hoạt động cung cấp dịch vụ đảm bảo chất lượng, tuy nhiên chưa có mục tiêu riêng biệt trong từng năm và trong từng giai đoạn. Với cở sở vật chất, bệnh viện chưa đáp ứng được chất lượng như mong đợi của khách hàng; về trang thiết bị, phòng thủ thuật đảm bảo an toàn cao.

\section{BÀN LUẬN}

Các bệnh võng mạc mạch máu là một trong các nguyển nhân hàng đâu gây mù lòa trên thế giới và tại Việt Nam.[3] Bệnh võng mạc mạch máu có thể được điều trị bằng các phương pháp khác nhau như laser hay tiêm nội nhãn. Tiêm nội nhãn bằng các chất ức chế tăng sinh nội mạc mạch như thuốc bevacizumab là một biện pháp điểu trị có hiệu quả với các bệnh này, giúp cải thiện thị lực và dự phòng mù lòa[6-8]. Tuy nhiên, tiêm nội nhã̉n cần được thực hiện định kỳ, nhiều lần và đòi hỏi sự cam kết của bểnh nhân về tài chính cũng như thời gian. Chất lượng dịch vụ là một trong các yếu tố quan trọng để giúp bệnh nhân tuân thủ điều trị[2]. Đây là nghiên cứu đầu tiên tiến hành về chất lượng dịch vụ này với mục đích đánh giá một cách tổng quan về thực trạng chất lượng cung cấp dịch vụ qua góc nhìn, cảm nhận của khách hàng sử dụng dịch vụ.

Kết quả nghiên cứu của chúng tôi cho thấy ngoài kết quả điều trị chuyên môn, Bệnh viện Mắt Trung Ương cũng đã thực hiện khá tốt việc cung ứng các dịch vụ trong thời gian điều trị, điêu này được thể hiện qua kết quả đánh giá trung bình đạt 4,24 điểm trên trên thang đo Likert có giá trị tối đa 5 điểm và cả 05 khía cạnh đều cho kết quả $>4,0$ điểm, trong 22 tiểu mục quan sát có 21 tiểu mục đạt $>4,0$ điểm, duy 
nhất 01 tiểu muc có số điểm < 4,0 (đat 3,77 điểm). Điểm CLDV TB chung trong nghiên cứu của chúng tôi cao hơn so với những nghiên cứu khác như trong nghiên cứu của Al-Damen (2017) tai Jordan là 3,06 $\pm 0,82$.[9] Nghiên cứu của Kitapei tại Thổ Nhĩ Kỳ có điểm CLDV hữu hình cao nhất tương tự như nghiên cứu chúng tôi. Các nghiên cứu khác tiến hành trong nước của Lê Thị Kim Ngân và Lê Thị Thu Trang, Nguyễn Đăng Minh tiến hành trên các bệnh viện cấp độ khác nhau đều cho thấy CLDV yếu tố hữu hình là thấp nhất.

Trong số 10 tiểu mục khách hàng đánh giá cao hơn điểm trung bình chung (4,24 điểm) thì có 06 yếu tố thuộc về nhân viên y tế, kết quả này cho thấy bệnh viện đã rất quan tâm đến việc nâng cao chất lượng đội ngũ nhân viên y tế, thực hiện tốt chủ trương của ngành $Y$ tế trong việc đổi mới phong cách, thái độ phục vụ của nhân viên y tế hướng đến sự hài lòng người bệnh.

\section{KẾT LUẬN}

Kết quả nghiên cứu cho thấy người bệnh đánh giá tốt chất lượng dịch vụ tiêm nội nhãn do Bệnh viện Mắt Trung Ương cung cấp. Trong các yểu tố cấu thành nên chất lượng dịch vụ, yếu tố thuộc về NVYT được đánh giá cao từ người bệnh. Bệnh viên cần tiếp tục duy trì các biện pháp tăng cường chất lượng dịch vụ trong thời gian tới

\section{TÀI LIÊU THAM KHẢO}

1. J. Joseph Cronin JaSAT. Measuring Service Quality: A Reexamination and Extension. Journal of Marketing. 1992;56:55-68.

2. P Tan Le, G Fitzgerald (2014) 'Applying the SERVPERF Scale to Evaluate Quality of Care in Two Public Hospitals at Khanh Hoa Province, Vietnam'. Asia Pacific Journal of Health Management 9(2).

3. Advances in the Medical Treatment of Diabetic Retinopathy Diabetes Care [Internet]. [cited 2021 May 12]. Available from: https://care. diabetesjournals.org/content/32/8/1556.short

4. Multicenter trial of cryotherapy for retinopathy of prematurity. Preliminary results. Cryotherapy for Retinopathy of Prematurity Cooperative Group. Arch Ophthalmol. 1988 Apr;106(4):471-9.

5. Watkins PJ. Retinopathy. BMJ. 2003 Apr 26; 326(7395):924-6.

6. Mason JO, Nixon PA, White MF. Intravitreal Injection of Bevacizumab (Avastin) as Adjunctive Treatment of Proliferative Diabetic Retinopathy. American Journal of Ophthalmology. 2006 Oct 1;142(4):685-8.

7. Arab M Ghazi Tabatabaei S Rashidian A Rahimi Forushani A Zarei E (2012) 'The Effect of Service Quality on Patient loyalty a Study of Private Hospitals in Tehran, Iran-annotated-annotated'. Iranian Journa of Public Health, 41 (9) 71-77.

8. The CATT research group (2011) 'Ranibizumab and bevacizumab for Neovascular Aged-Related Macular Degeneration' The New England Journal of Medicine; 364:1897-1908.

9. Rula Al-Damen (2017) "Health Care Service Quality and Its Impact on Patient Satisfaction Case of Al-Bashir Hospital'"'. International Journal of Business and Management, 12 (9).

\section{PHÂN TÍCH HÀNH VI MUA THỨC PHẨM CHỨC NĂNG CỦA NGƯờI TIÊU DÙNG TẠI THÀNH PHỐ HỒ CHÍ MINH}

Nguyễn Thị Thu Sương², Nguyễn Thị Thu Phương1, Trần Thoại Khanh', Trương Văn Đạt ${ }^{1}$, Đặng Thị Kiều Nga ${ }^{1}$, Nguyễn Thị Hải Yến ${ }^{1}$

\section{TÓM TẮT}

Muc tiêu: Phân tích tình hình sử dung FF từ mô hình hành vi mua của người tiêu dùng tại Thành phố Hồ Chí Minh năm 2019. Phương pháp nghiên cứu: Nghiên cứu mô tả cắt ngang sứ dụng phương pháp đinh tính và định lương thông qua việc khảo sát người tiêu dùng tại các nhà thuốc trên địa bàn TPHCM có kinh doanh đa dạng TPCN năm 2018. Kết quả: Các yếu tố có tác động đến sự chấp nhận của người tiêu

${ }^{1}$ Đại học Y Dược Thành Phố Hồ Chí Minh ${ }^{2}$ Sở Khoa hoc và Công nghể Thành Phố Hồ Chí Minh Chịu trách nhiệm chính: Nguyễn Thị Hải Yến Email: haiyen@ump.edu.vn

Ngày nhận bài: 8.3.2021

Ngày phản biên khoa hoc: 27.4.2021

Ngày duyệt bài: 7.5.2021 dùng đối với TPCN bao gồm: (1) Thái độ, (2) Kiến thức, (3) Niềm tin, (4) Giá cả. Kết quả nghiên cứu cũng cho thấy "niềm tin" ảnh hưởng mạnh nhất đến mức đô chấp nhân của người tiêu dùng. Khi người tiêu dùng tin tưởng vào những lợi ích đối với sức khỏe mà TPCN có thể mang lai thì người tiêu dùng có khuynh hướng chấp nhận TPCN cao hơn. Kết luận: Lưu ý hành vi mua của người tiêu dùng trong quá trình phát triển và quảng bá sản phẩm của doanh nghiêp đến với người tiêu dùng cũng như trong các hoat đông tiếp thi của mình đảm bảo vì lợi ích sức khoẻ người tiêu dùng và phát triển thị trường TPCN.

Từ khóa: hành vi mua, thực phẩm chức năng, phân tích nhân tố, phân tích hồi quy tuyến tính, Thành phố Hồ Chí Minh

\section{SUMMARY}

ANALYSIS OF CONSUMER'S BUYING 